\title{
Development of peripheral chemoreceptor function in infants with chronic lung disease and initially lacking hyperoxic response
}

\author{
Miriam Katz-Salamon, Mats Eriksson, Baldvin Jónsson
}

\begin{abstract}
Ten preterm infants with chronic lung disease (CLD) and undeveloped peripheral chemoreceptor function, described as ventilatory response to hyperoxia, were investigated, according to an individual protocol. Each infant was followed up until the response to hyperoxic inhalation had been observed on two occasions. Each examination consisted of overnight recording of saturation, testing of lung compliance and airway resistance, and the hyperoxic test.
\end{abstract}

The hyperoxic response appeared at a mean postnatal age of 14 weeks (range 9-33 weeks). This response, which was independent of the infant's lung mechanics, appeared much later in infants with the severe form of CLD.

As undeveloped peripheral chemoreceptor function has been suggested to be a key factor in sudden infant death syndrome (SIDS), the delayed development of their chemosensitivity leaves some infants with CLD unprotected against hypoxia at the age at which the risk for SIDS is highest.

(Arch Dis Child 1996;75:F4-F9)

Keywords: peripheral chemoreceptors, CLD, SIDS.

Infants with chronic lung disease (CLD) usually exhibit frequent episodes of hypoxaemia, due to episodes of desaturation, ${ }^{1-4}$ decreased lung compliance, and increased airways resistance. ${ }^{5}$ Furthermore, when exposed to hypoxia, these infants often respond with initial arousal, followed by prolonged apnoea and bradycardia. ${ }^{6}$ Desaturations may adversely affect the sensitivity of peripheral chemoreceptors and, as shown in animal models, result in severe disturbances in respiratory control mechanisms, ${ }^{7}$ in the absence of arousal from hypoxia ${ }^{8}$ or in sudden death. ${ }^{9}$ It has been suggested that absent or attenuated peripheral chemoreceptor function may, at least partially, explain the significantly increased incidence of sudden infant death syndrome (SIDS) in these infants. ${ }^{6-11}$

In previous studies we have shown that prolonged oxygen treatment attenuates the sensitivity of peripheral chemoreceptors, ${ }^{12}$ and that most infants with CLD had defective function of peripheral chemoreceptors. ${ }^{13}$ This prompted us to investigate whether adequate responsiveness of these receptors in infants with CLD develops subsequently during recovery from the disease or whether the observed dysfunction is permanent.

Because exposure to hyperoxic gas mixtures causes an almost immediate suppression of the action of peripheral chemoreceptors, ${ }^{14}$ an oxygen induced decrease in ventilation has been used as an indirect measure of the sensitivity of these receptors.

\section{Methods}

Ten infants treated at Karolinska Hospital were included in this study on the basis of two criteria: they were diagnosed as having CLD; and they displayed an initial absence of the response to hyperoxia.

CLD was diagnosed on the basis of the following criteria:

(1) an acute lung injury during the first week of life;

(2) clinical signs of chronic respiratory disease;

(3) a requirement for supplemental oxygen in order to maintain a $\mathrm{PaO}_{2}$ of over $50 \mathrm{~mm} \mathrm{Hg}$ for more than 28 days;

(4) a chest radiograph showing persistent strands of density in both lungs. ${ }^{15}$

CLD was divided into stages according to the criteria described by Toce et al. ${ }^{17}$ In addition to the criteria mentioned above, the respiratory status of the infants was also determined with regard to the amount, duration, and depth of spontaneous desaturations during the night preceding the test, and by lung compliance and airways resistance at the time of the test.

Informed consent from the parents was obtained and the examination was often performed in the presence of at least one parent. This study was approved by the local ethics committee at the Karolinska Hospital

RESPIRATORY RECORDINGS

Ventilatory measurements were performed using a neonatal/infant pulmonary monitor (Bicore, CP-100) which provides continuous pulmonary monitoring of airway flow and pressure through a flow transducer. The 
Experimental procedure - timing and structure

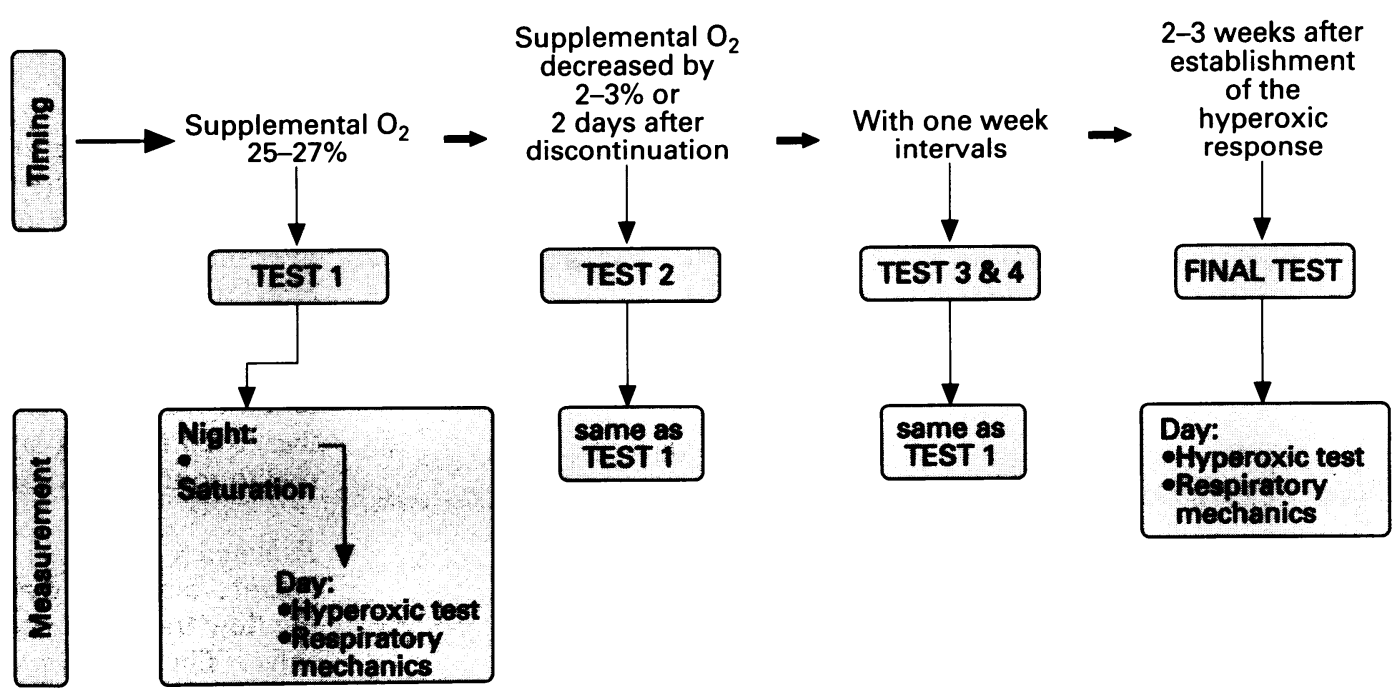

Figure 1 Timing and structure of experimental protocol. The timing of measurements was based on the infant's requirement for supplemental oxygen. All measurements, except for the final test, included overnight recording of the saturation and daytime recording of respiratory mechanics and administration of the hyperoxic test.
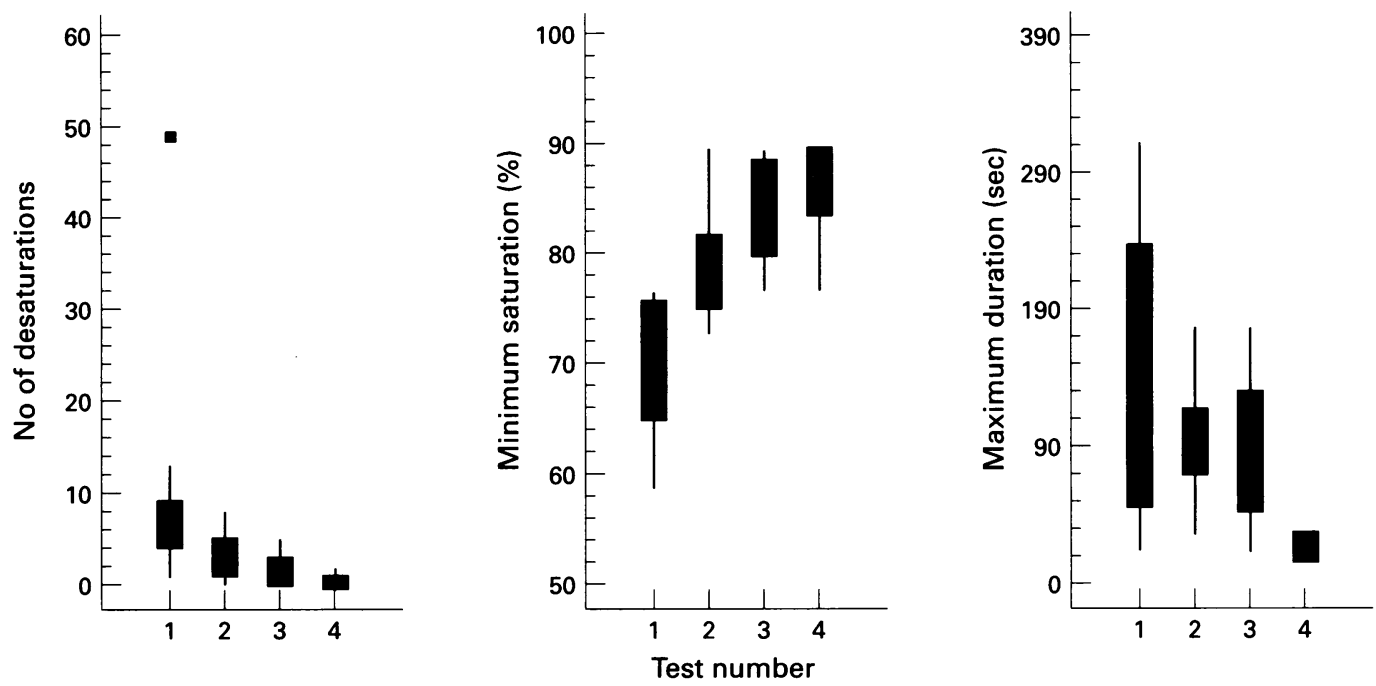

Figure 2 Time related changes in the number, depth, and duration of spontaneous desaturations during the night before each test. Medians are indicated by bold horizontal lines. The rectangles show $50 \%$ of the values-that is, all values above the lower and below the upper quartiles. The bars extend to the minimum and maximum values, while the one outlying value observed ( $a$ value 1.5 times above or below the interquartile range) is indicated by a small square.

sampling frequency of the system for pressure and flow is $100 \mathrm{~Hz}$ and the response time 13.5 ms. By using a flow transducer together with an occlusion valve, airway pressure, compliance, and respiratory resistance could be measured. During the hyperoxic test, the flow head was connected via a T-tube to a stream of 4

Table 1 Patient data

\begin{tabular}{|c|c|c|c|c|c|c|c|c|c|}
\hline Case No & $\begin{array}{l}\text { Gestational } \\
\text { age at } \\
\text { birth } \\
\text { (weeks) }\end{array}$ & $\begin{array}{l}\text { Birth } \\
\text { weight }(g)\end{array}$ & $\begin{array}{l}\text { Ventilator } \\
\text { treatment } \\
\text { (days) }\end{array}$ & $\begin{array}{l}C P A P \\
\text { (days) }\end{array}$ & $\begin{array}{l}\mathrm{O}_{2} \text { treatment } \\
\text { (days) }\end{array}$ & $\begin{array}{l}\text { CLD } \\
\text { grade }\end{array}$ & $\begin{array}{l}\text { Diuretic } \\
\text { treatment }\end{array}$ & $\begin{array}{l}\text { Inhaled } \\
\text { bronchodilators } \\
\text { (Salbutamol) }\end{array}$ & $\begin{array}{l}\text { Inhaled } \\
\text { steroids } \\
\text { (Budesonide) }\end{array}$ \\
\hline 1 & 32 & 1766 & 8 & 18 & 49 & I & No & No & Yes \\
\hline 2 & 27 & 877 & 5 & 45 & 72 & I & Yes & No & Yes $/ \mathrm{No}^{\star}$ \\
\hline 3 & 25 & 753 & $3 \cdot$ & 75 & $245 \dagger$ & III & Yes & Yes & Yes \\
\hline 4 & 24 & 837 & 21 & 44 & 74 & II & Yes & No & No \\
\hline 5 & 24 & 832 & 18 & 38 & 64 & I & Yes & No & No \\
\hline 6 & 27 & 1095 & 17 & 37 & 113 & II & Yes & No & Yes $/ \mathrm{No}^{\star}$ \\
\hline 7 & 26 & 709 & 18 & 11 & 105 & II & Yes & No & No \\
\hline 8 & 28 & 1250 & 14 & 33 & 54 & I & Yes/No* & No & No \\
\hline 9 & 25 & 657 & 6 & 159 & $352 t$ & III & Yes & Yes & Yes \\
\hline 10 & 25 & 877 & 0 & 36 & 67 & I & Yes/No* & No & No \\
\hline
\end{tabular}

*Yes/No = treatment interrupted during the course of study. † Receiving supplemental oxygen at time of discharge home.
$1 /$ minute humidified, warmed air that could be rapidly switched to $4 \mathrm{l}$ /minute $100 \%$ humidified, warmed oxygen. The dead space of the mask, flow head, and tubing was $2-3 \mathrm{ml}$ and their total resistance was $7.1 \mathrm{~cm} \mathrm{H}_{2} \mathrm{O} / 1 / \mathrm{s}$. The respiratory parameters-that is, minute ventilation, inspiratory/expiratory tidal vol- 

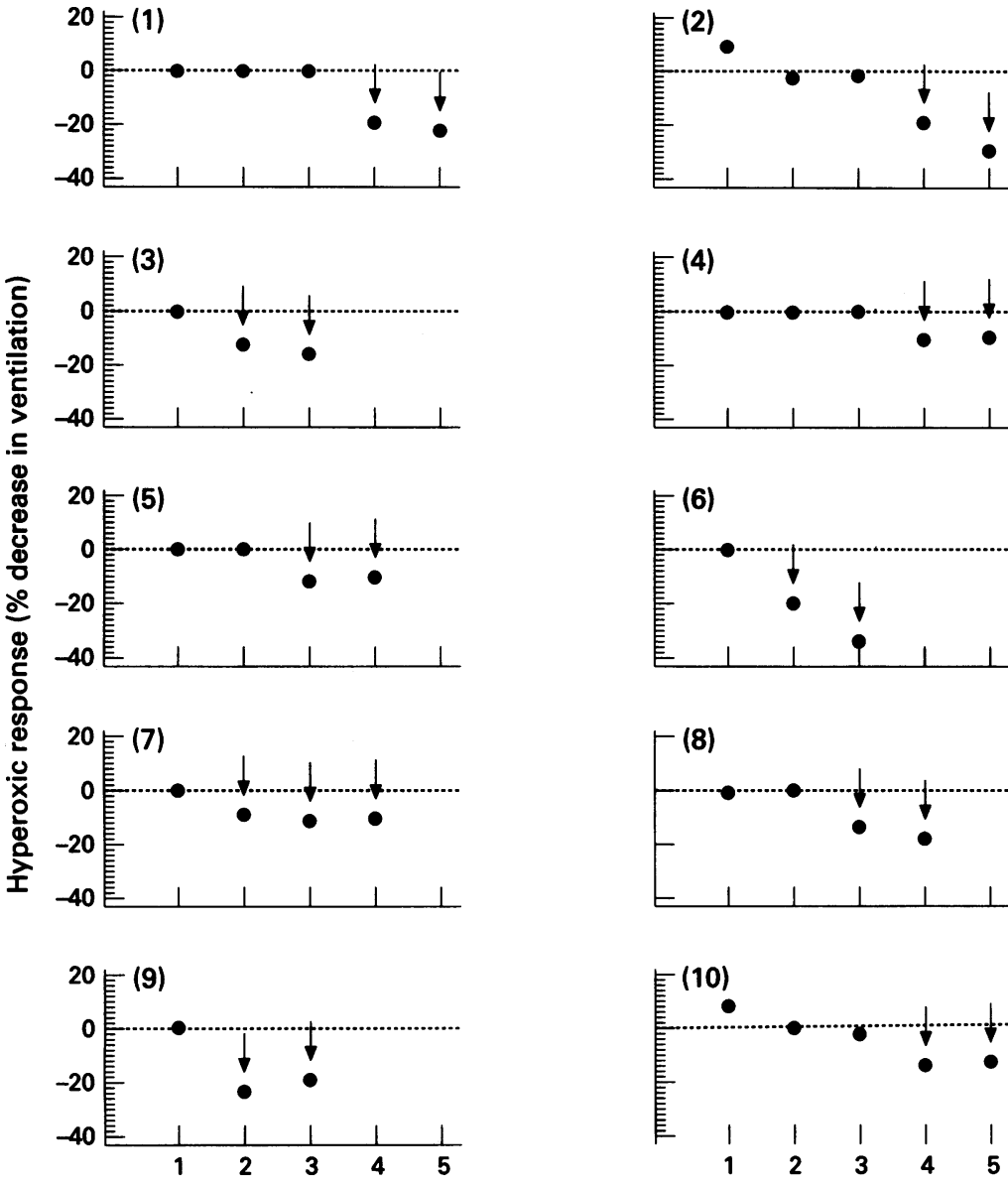

Test number

Figure 3 Development of the hyperoxic test in the 10 patients. The arrows indicate the significant responses; the dotted line indicates no response.

ume, respiratory rate and inspiratory/expiratory duration-were stored and analysed by computer.

Oxygenation was measured using a pulse oxymeter probe (Respitrace, Studley Data System, Oxford, UK).

EXPERIMENTAL PROCEDURE

The time schedule and number of tests were decided individually for each infant, on the basis of his or her dependency on supplemental oxygen and the time at which the hyperoxic response appeared. The principles of the timing and the structure of the study are described schematically in fig 1 .

\section{Saturation}

An overnight recording was made immediately before the daytime test and analysed for the number, duration, and the level of desaturations.

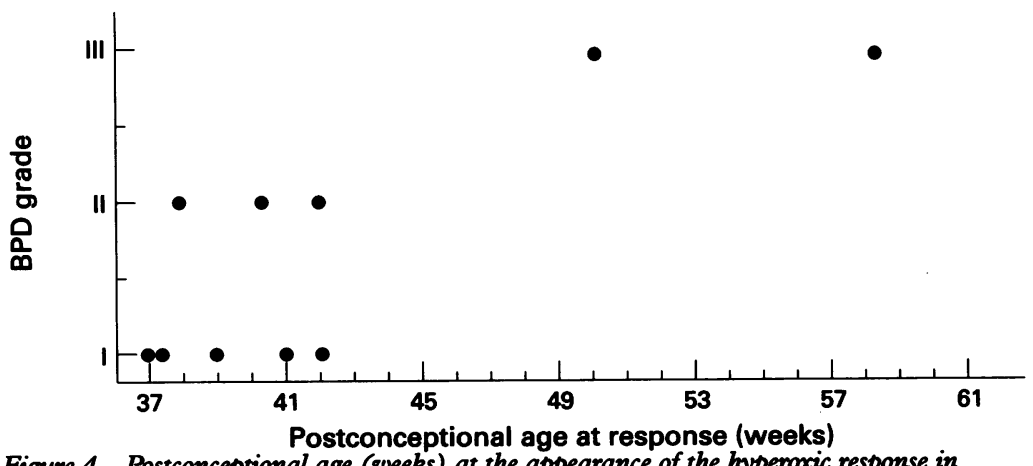

Figure 4 Postconceptional age (weeks) at the appearance of the hyperoxic response in relation to grade of $C L D$
Hyperoxic test

The infants were loosely wrapped in blankets in their cots. All examinations were performed during behavioural quiet sleep, characterised by the absence of eye and body movements and by regular respiration. ${ }^{18}$ The face mask was gently placed on the infant's face. The test was initiated by three to five minutes of stable breathing with warmed, humidified air. Thereafter, the inspiratory line was rapidly switched and the infant breathed $100 \%$ humidified oxygen for 30 seconds, followed by readministration of air. This test was repeated five to 10 minutes later. During every session, two to four tests were performed.

\section{Pulmonary mechanics}

Infants breathed through the face mask into the flow transducer connected to the occlusion valve. The airways were occluded automatically at the end of inspiration and the accompanying volume/pressure and pressure/ flow correlations described respiratory system compliance $\left(C_{r s}\right)$ and resistance $\left(R_{r s}\right)$. All data were stored on the computer.

\section{ANALYSIS OF THE RESULTS}

Recordings were considered satisfactory for analysis only if the baby remained in the same position without sudden movement, in continuous behavioural quiet sleep.

\section{Saturation}

Box and whisker plots were used to describe desaturations. This analysis provides the range and median and is useful for studying symmetry and detecting out of range data.

\section{Response to hyperoxia}

Tidal volume, breath duration, and minute ventilation were analysed on a breath by breath basis for each individual. Ventilatory variables were calculated for the 30 seconds of air breathing immediately preceding the hyperoxic test, during the 30 seconds of oxygen administration, and during the first minute of recovery by breathing air. The mean values from three to four trials were calculated and used for analysis. Percentage changes in the tidal volume, breath duration, and minute ventilation on going from normoxic to hyperoxic conditions were determined for each infant and tested for significance by analysis of variance.

\section{Clinical status and hyperoxic response}

Possible correlations between the age at which the hyperoxic response developed and grade of CLD, postconceptional age at birth, birthweight, days on a ventilator and on continuous positive airway pressure (CPAP), duration of supplemental $\mathrm{O}_{2}$ treatment, and the number, duration, and depth of desaturations were examined using multiple regression analysis.

Possible relationships between the grade of CLD and respiratory system compliance $\left(\mathrm{C}_{\mathrm{rs}}\right)$, airway resistance $\left(R_{\mathrm{rs}}\right)$, and the strength of the hyperoxic response were evaluated using the Spearman Rank correlation.

The time dependent changes in $\mathrm{C}_{\mathrm{rs}}$ and $\mathrm{R}_{\mathrm{rs}}$ in all patients were evaluated using the analysis 

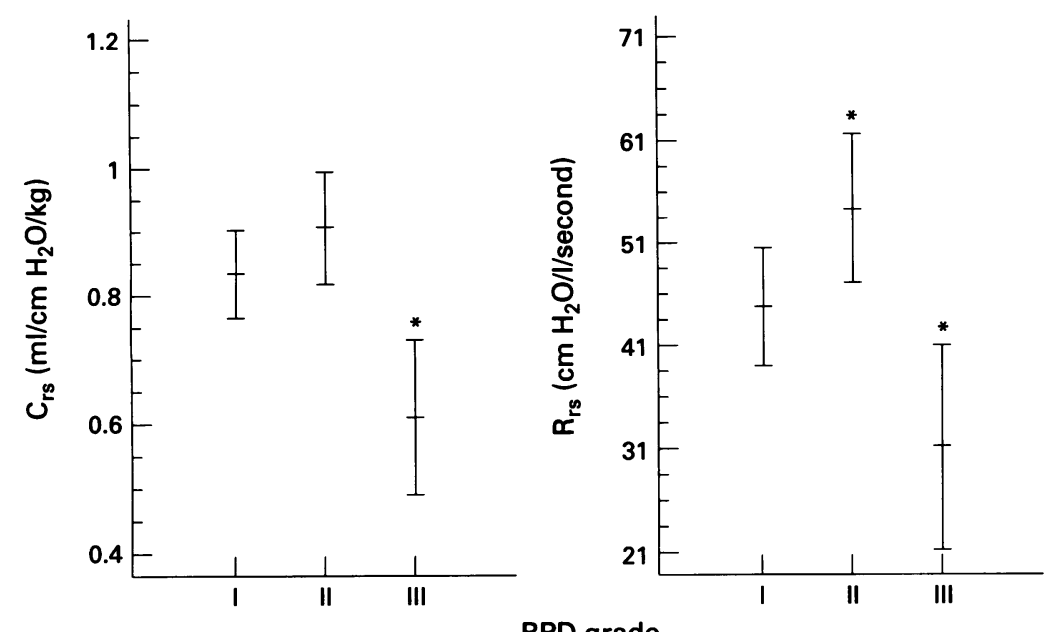

Figure 5 Respiratory system compliance $\left(C_{r s}\right)$ and resistance $\left(R_{r s}\right)$ in relation to grade of $C L D$. Mean (SD) values for all tests are shown. ${ }^{*}$ indicates significant difference from mean value for infants with grade I $B P D$.

of variance test for homogeneity, which examines the differences between several subgroups of data.

\section{Results}

The patient data are presented in table 1 . The mean postconceptional age at birth and mean (SD) birthweight were 26.3 (2.4) weeks and 965 (332) g, respectively. The length of time
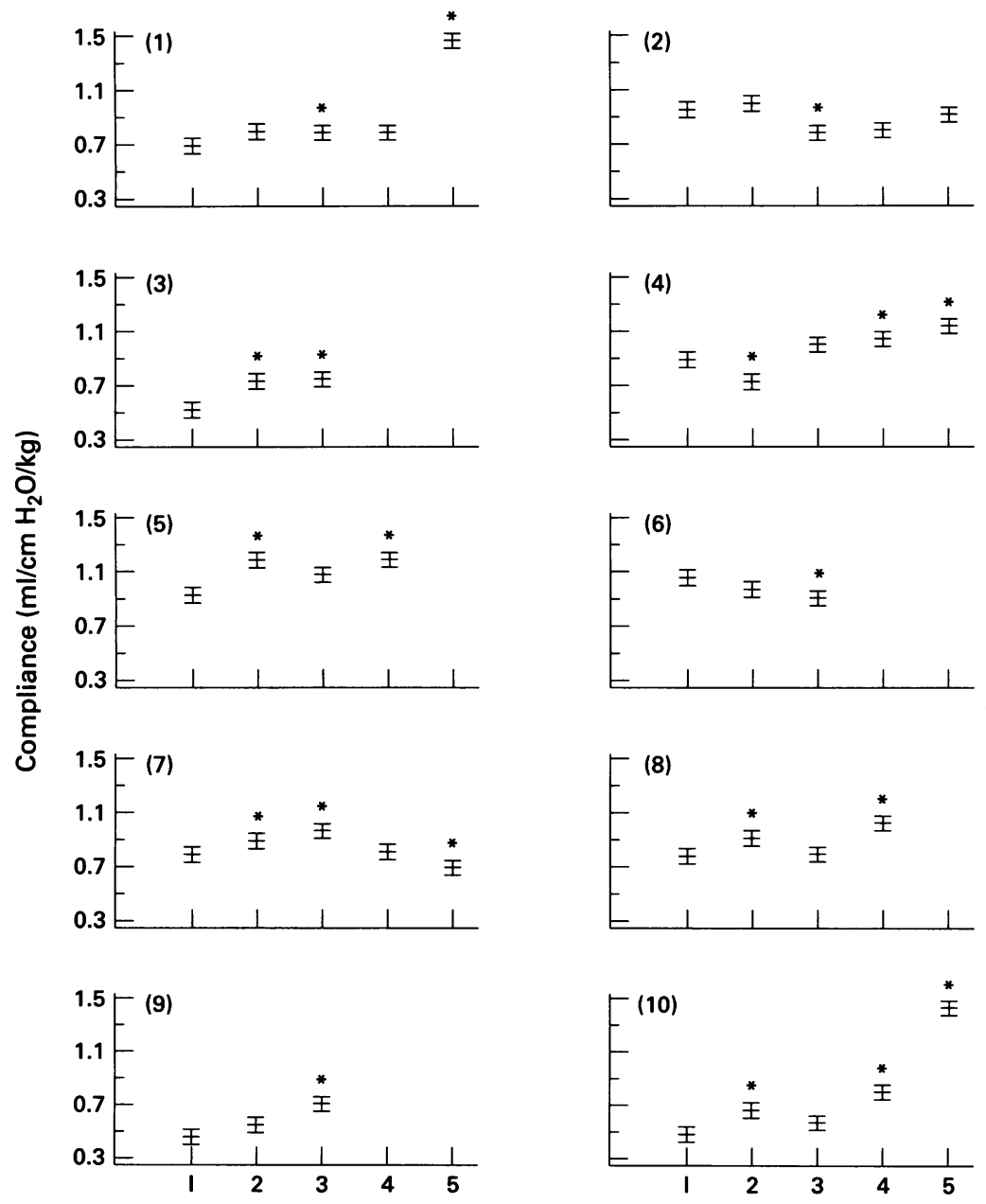

\section{Test number}

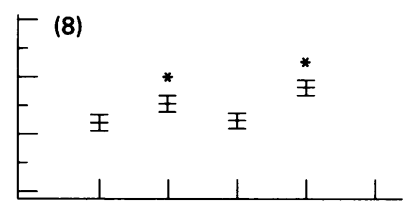

Figure 6 Time related changes in $C_{r s}$ for each infant. * indicates significant change from reading of first measurement.
Table 2 Postconceptional and postnatal ages of the infants at time of appearance of hyperoxic response

\begin{tabular}{llll}
\hline Case No & $\begin{array}{l}\text { Postconceptional } \\
\text { age (weeks) }\end{array}$ & $\begin{array}{l}\text { Postnatal age } \\
\text { (weeks) }\end{array}$ & $\begin{array}{l}\text { Supplemental } \\
\text { oxygen (\%) }\end{array}$ \\
\hline 1 & 42 & 10 & None \\
2 & 41 & 14 & None \\
3 & 50 & 25 & 23 \\
4 & 38 & 15 & None \\
5 & 37 & 13 & None \\
6 & 40 & 13 & 23 \\
7 & 42 & 16 & None \\
8 & 37 & 9 & None \\
9 & 58 & 33 & 25 \\
10 & 39 & 14 & None \\
\hline
\end{tabular}

on ventilator support varied between 0 (one infant) and 21 days, while the number of days on CPAP ranged between 11 and 159 days. Supplemental oxygen was provided for a mean period of 120 days (range from 49 to $>352$ days). Two infants (cases 3 and 9), were still receiving oxygen at the time of discharge home. Five infants had grade I CLD, three grade II, and two grade III.

The median number of desaturations per night decreased with increasing age from 5.5 at the time of the first test to 0 at the last test (the mean decreased from 10 to 0.6 desaturations per night). At the same time, the duration and depth of the desaturations decreased (fig 2).

All infants developed sensitivity to hyperoxia before being discharged, at the times indicated by the arrows in fig 3 . Once established, this response either remained unchanged (in seven infants), or became even stronger (in three infants). The median postnatal and postconceptual age at which the hyperoxic response was established were 14 weeks (range 9-33 weeks) and 41 weeks (range 37-58 weeks), respectively (table 2 ).

The more severe cases of CLD showed delayed appearance of the hyperoxic response (fig 4). There was a significant correlation $(P=0.02)$ between the postnatal age at which the response appeared and the grade of CLD; postconceptual age was not associated with the time for establishment of this response $(P=0.057)$. Three of the infants were still receiving supplemental oxygen when they developed the hyperoxic response (table 2). Two of these had the highest postnatal and postconceptual ages. On the other hand, the strength of the response was related neither to the postconceptual or postnatal age of the infant, nor the grade of CLD. The response time was not correlated with the CLD the grade or strength of the response.

The repeated measurements of $\mathrm{C}_{\mathrm{rs}}$ on the same test, varied by a mean of $7.3 \%$ (range 4-10\%), which was significantly lower than the differences between individuals (ANOVA; $P<0.000$ ). The measurements of $R_{r s}$ showed much higher variations (mean of $17.2 \%$ and range of $11-25 \%$ ).

The two infants with grade III CLD had significantly lower $C_{r s}(P=0.001)$ and lower $R_{r s}$ $(P=0.002)$ then the other infants (fig 5). The time dependent changes in $\mathrm{C}_{\mathrm{rs}}$ and $\mathrm{R}_{\mathrm{rs}}$ are shown in figs 6 and 7 . The stars denote a significant difference from the first test (using the Mann-Whitney $U$ test). In two infants the 

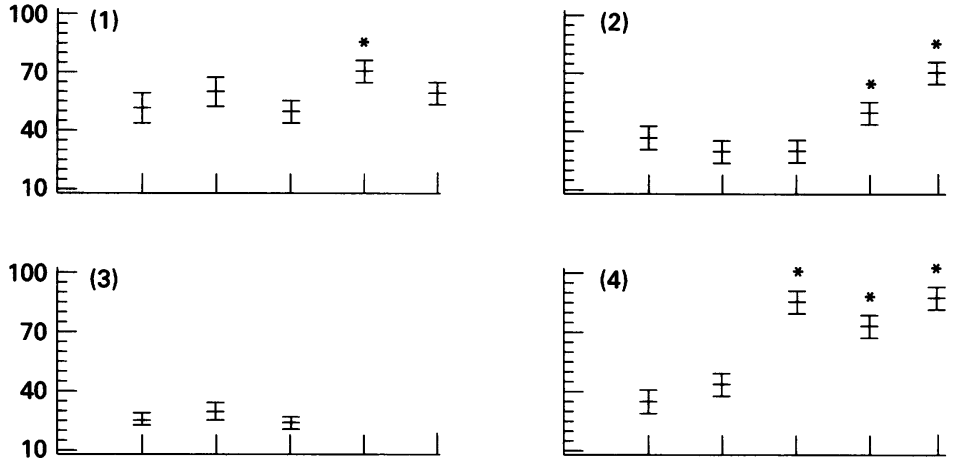

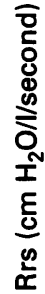
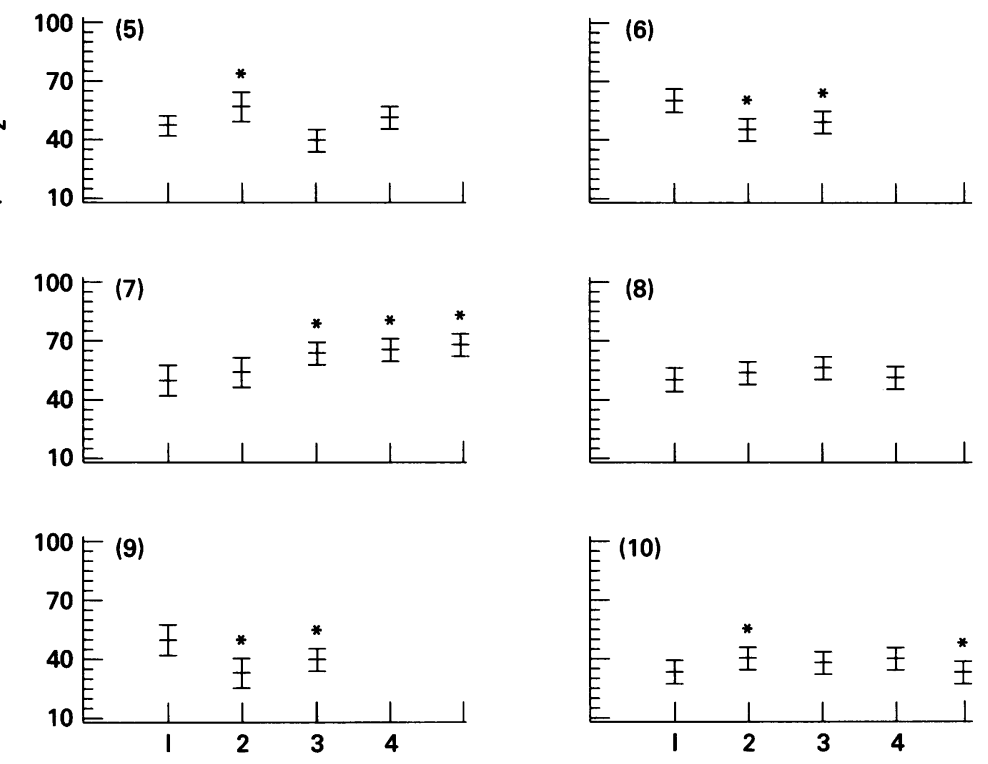

Test number

Figure 7 Time related changes in $R_{r s}$ for each infant. * indicates significant change from first measurement. of peripheral chemoreceptor function (present study) and has been associated with the time period for increased risk of SIDS. ${ }^{21} 22$

The delayed development of chemoreceptor function at the age where the susceptibility to SIDS is highest suggests that some infants with more severe CLD lack the ability to defend themselves when subjected to hypoxia. Although only a small number of patients were investigated in the present study, our findings support the hypothesis that defective peripheral chemoreceptor function is a contributory factor to SIDS..$^{23}$ Therefore, an effort should be made to identify additional risk factors that might predispose infants with CLD to SIDS.

On the basis of an epidemiological study of very preterm and small for postconceptual age infants in the Netherlands, maternal smoking, hypothermia on the first day of life, and a decreased number of white cells and thrombocytes at birth were proposed as perinatal risk factors for SIDS. ${ }^{22}$ Intrauterine hypoxia was suggested as the common denominator for these risk factors. Similarly, postnatal hypoxia was suggested as a risk factor for SIDS, because a substantial proportion of SIDS babies have chronic pulmonary hypoventilation, respiratory distress syndrome, and hypoxaemia. ${ }^{24-27}$ Short hypoxaemic episodes in the form of frequent desaturations have recently been observed in infants with CLD. ${ }^{1-4}$ In our study group the infants also initially sustained desaturations during sleep, despite treatment with supplemental oxygen. The decrease in the frequency and duration of night time desaturations, which was not parallelled by an improvement in respiratory mechanics, might be explained by maturation of the ventilatory control mechanisms. The possible connection between the desaturations and impaired lung mechanics is particularly important, as in infants with CLD the hypoxic episodes might be potentiated by obstruction in the airways and by the inability to compensate for this kind of respiratory loading. ${ }^{28}$ Surprisingly, the infants in our study who had the most severe CLD (grade III) showed the lowest airway resistance. However, the explanation for this could be simple. The examination of the infants was performed within two to three hours of treatment with bronchodilators administered to alleviate severe initial obstruction.

The preceding hypoxaemia in SIDS babies is associated with pathological changes in the glomi of carotic bodies. ${ }^{29} 30$ Hypoxaemic episodes also result in histological and chemical changes in the brain, ${ }^{31-33}$ and might therefore even affect the respiratory control centres localised in the brain stem. The negative effect of hypoxaemia on peripheral, as well as on central, structures might contribute to an increased susceptibility to SIDS.

Even though this hypothesis does not provide an aetiological explanation for SIDS, it might shed light on the mechanisms underlying susceptibility to SIDS among very low birthweight infants who often experience both perinatal and postnatal hypoxia. The importance of precluding hypoxic episodes as a prepostnatal age (6 and 8 months). This is particularly interesting, because postnatal age is significantly correlated with the development 
ventive measure against SIDS has recently been emphasised by Gray and Rogers, ${ }^{34}$ who showed that treatment of infants with CLD with supplemental oxygen once they had returned home lowered their risk for SIDS to normal levels.

Most infants with CLD with the initial absence of a peripheral chemoreceptor response to hyperoxia subsequently develop this at about 14 weeks after birth. However, most severely affected infants still lack the response at the age at which the strongest susceptibility to SIDS occurs, and so must be carefully monitored.

We thank Dr. Monique Bonora, Gaby van Welsen, Marijke Hoffstra and Gisela Hellgren for their skilful and devoted assisHoffstra and Gisela Hellgren for their skilful

tance during the initial part of this project. This study was supported by grants from the Bank of Sweden Tercentenary Foundation, the Swedish Medical Research
(grant B95-27X-11265-01A), and the AGA foundation.

1 Sekar KC, Duke JC. Sleep apnea and hypoxemia in recently weaned premature infants with and without bronchopulmonary dysplasia. Pediatr Pulmonol 1991;10:1 12-16.

2 Singer L, Martin RJ, Hawkins SW, Benson-Szekely LJ, Singer L, Martin RJ, Hawkins SW, Benson-Szekely LJ,
Yamashita TS, Carlo WA. Oxygen desaturation compliYamashita TS, Carlo WA. Oxygen desaturation complicates feeding in infants with bronchopul
after discharge. Pediatrics 1992;90:380-4

3 Durand M, McEvoy C, MacDonald K. Spontaneous desaturations in intubated very low birth weight infants with acute and chronic lung disease. Pediatr Pulmono 1992;13:136-42.

4 Zinman R, Blanchard PW, Vachon F. Oxygen saturation during sleep in patients with bronchopulmonary dysplasia. Biol Neonate 1992;61:69-75.

5 Greenspan JS, Abbasi S, Bhutani VK. Sequential changes in pulmonary mechanics in the very low birth weight $(1000$ pulmonary mechanics in the very low birth

6 Garg M, Kurzer S, Bautista D, Keens T. Hypoxic arousal in infants with bronchopulmonary dysplasia. Pediatrics 1988; 82: $59-63$

7 Hofer MA. Role of carotic sinus and aortic nerves in respiratory control of infant rats. Am $\mathcal{F}$ Physiol 1986;251 811-17.

8 Fewell JE, Kondo CS, Ddascalu V, Filyk SC. Influence of carotic denervation on the arousal and cardiopulmonary response to rapidly developing hypoxemia in lambs. Pediat Res 1989;25:473-9.

9 Hunt CE, McCullogh K, Brouillette RT. Diminished hypoxic ventilatory responses in near-miss sudden infant death syndrome. $\mathcal{F}$ Appl Physiol 1981;50:1313-17.

10 Werthammer J, Brown ER, Neff RK, Taeusch HW. Sudden Infant Death Syndrome in infants with bronchopulmonary dysplasia. Pediatrics 1982;69:301-4.

11 Calder NA, Williams BA, Smyth J, Boon AW, Kumar P, Hanson MA. Absence of ventilatory response to alternating breaths of mild hypoxia and air in infants who have had bronchopulmonary dysplasia: implications for the risk of sudden infant death. Pediatr Res 1994;35:677-81.

12 Katz-Salamon $M$, Lagercrantz $H$. Hypoxic ventilatory defence in very preterm graduates - attenuation after longoxygen treatment. Arch Dis Child 1994;70:90-5.
13 Katz-Salamon $M$, Jonsson $B$, Lagercrantz $H$. Blunted Peripheral chemoreceptor response to hyperoxia in a group of

14 Cross KW, Oppe TE. The effect of inhalation of high and low levels of oxygen on the respiration of the premature infant. F Physiol 1952;117:38-55.

15 Bancalari E, Abdenour GE, Feller R, Gannon J. Bronchopulmonary dysplasia: Clinical presentation. $\mathcal{F}$ Pediatr 1979 85:819-23.

16 O'Brodovich HM, Mellins RB. Bronchopulmonary dysplasia . Unresolved neonatal acute lung injury. Am Rev Respir Dis 1985;32:694-709.

17 Toce S, Farrel PH, Leavitt LA, Samuels DP, Edvards DK Clinical and roentgenographic scoring systems for assessing bronchopulmonary dysplasia. Am $\mathcal{f}$ Dis Child 1984, 138:581-5.

18 Prechtl HV. The behavioral states of the newborn infant. Brain Res1974;76:185-212.

19 Bolton DP. The prevalence of immature respiratory control in a neonatal population. NZ Med F 1990;103:89-92.

20 Brady JP, Ariagno RL, Watts JL, Goldman SL, Dumpit FM. Apnea, hypoxemia and aborted sudden infant death syndrome. Pediatrics 1978;62:686-91.

21 Wagner M, Samson-Dolfus D, Menard J. Sudden unexpected death in a French county. Arch Dis Child 1984;59:1082-7.

22 Wierenga $H$, Brand $R$, Geudeke $T$, Geijn vad HP, Harten van der $\mathbf{H}$, Verloove-Vanhorick P. Prenaral risk factors for cot death in very preterm and small for postconceptual age infants. Early Hum Dev 1990;23:15-26.

23 Naeye RL, Fisher R, Ryser M, Whalen P. Carotic body in the sudden infant death syndrome. Science 1976;191:567-9.

24 Naeye RL, Ladis B, Drage JS. Sudden Infant death Syndrome. A prospective study. Am $\mathcal{F}$ Dis Child 1976; 130:1192-207.

25 Steinschneider A. Prolonged apnea and the sudden infant death syndrome: Clinical and laboratory observations. Pediatrics 1972;50:646-54.

26 Naeye RL. Hypoxemia and the sudden infant death syndrome. Science 1974;186:837-8.

27 Kendeel SR, Ferris JA. Apparent hypoxic changes in pulmonary and small arteries in infancy. $f$ Clin Pathol 1977;30:481-5.

28 Greenspan JS, Wolfson MR, Locke RG, Allen J, Shaffer $T H$. Increased respiratory drive and limited adaptation to loaded breathing in bronchopulmonary dysplasia. Pediat Res 1992;32:356-9.

29 Naeye RL. Pulmonary arterial abnormalities in the sudden infant death syndrome $N$ Engl f Med 1973;289:1167-170.

30 Heath D, Khan Q, Smith P. Histopathology of the carotic bodies in neonates and infants. Histopathology 1990 17:511-19.

31 Silverstein F, Johnston M. Effects of hypoxia-ischemia on monoamine metabolism in the immature brain. Ann Neurol 1984;15:342-7.

32 Williams C, Mallard C, Gluckman P. Perinatal asphyxia factors that alter degree and distribution of damage. In: Griesen G, Larsen JF, eds. Brain lesions in the newborn. Hypoxic and haemodynamic pathogenesis. Copenhagen: Munsgaard, 1994: 209-21.

33 Greisen G. Thresholds for periventricular white matter vulnerability in hypoxia-ischemia. In: Lou H, Griesen G, Larsen JF, eds. Brain lesions in the newborn. Hypoxic and haemodynamic pathogenesis. Copenhagen: Munsgaard, 1994: 222-33.

34 Gray PH, Rogers Y. Are infant with bronchopulmonary dysplasia at risk for sudden infant death syndrome? Pediatrics 1994;93:774-7. 